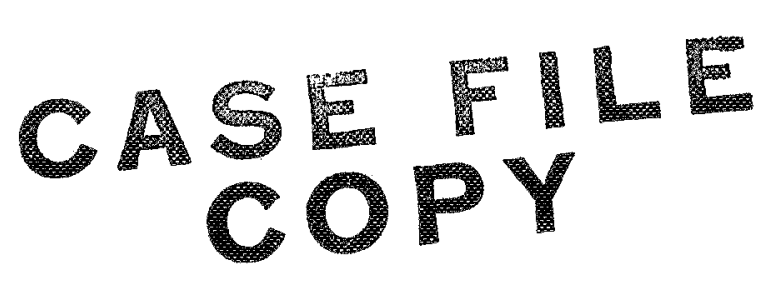

TESTS OF PERMANENT MAGNET AND SUPERCONDUCTING MAGNET MPD THRUSTERS

by Denis J. Connolly, Allen R. Bishop, and George $R$, Seikel

Lewis Research Center

Cleveland, Ohio

TECHNICAL PAPER proposed for presentation at Seventh Propulsion Joint Specialist Conference sponsored by the American Institute of Aeronautics and Astronautics Salt Lake City, Utah, June 14-18, 1971 


\section{TESTS OF PERMANENT MAGNET AND SUPERCONDUCTIVG MAGNET MPD THRUSTERS}

Denis J. Connolly, Allen R. Bishop, and George R. Seikel National Aeronautics and Space Administration Lewis Research Center

Cleveland, Ohio

\section{Abstract}

A radation cooled MPD thruster was tested with the magnetic field supplied by a permanent magnet. The magnet provided a field of 0.08 tesla at the cathode tip. At $25 \mathrm{~kW}$ are power the maximum magnet temperature was $835^{\circ} \mathrm{K}$. The total thruster weight was under $1 \mathrm{~kg} / \mathrm{kW}$. The MPD thruster was also tested with a superconducting magnet to investigate operation at varying magnetic field strengths up to 1 tesla. Some increase in power capability was obtained with increasing field. When this thruster was operated with argon propellant and a hollow cathode, arc efficiency was found to increase with applied magnetic field strength. At 1 tesla and $25 \mathrm{~kW}$ arc power, the efficiency exceeded 30 percent at 2000 sec specific impulse,

\section{Introduction}

Since about 1965, the MPD arc thruster has received a good deal of attention as a potentially useful space electric thruster. As indicated in a survey paper by Nerheim and Kelley, (I) early measurements indicated the MPD thruster could be quite efficient. In addition, impressive potential advantages were pointed out in the way of system simplicity and relative freedom from cumbersone power conditioning equipment. (2) These latter arguments assumed the thruster magnetic field could be supplied using permanent magnets or other lowweight, low-power consumption systems.

In the Lewis MPD thruster program, some effort was directed towards documenting the ability of a thruster to operate using permanent magnets. Permanent magnet design was analyzed,(3) and the first fully radiation cooled thruster was assembled using permanent magnets. This thruster was successfully operated and is reported on herein.

In previous MPD thruster tests, $(4,5)$ there were indications that efficiency improved with increasing arc power. Also, previous water. cooled thruster studies indicated that the percentage of arc power which was converted to anode heat was reduced with increasing magnetic field strength, (6) This suggests that increased magnetic field. strength would raise the arc power capability of a radiation cooled thruster. We thus constructed a superconducting magnet thruster as an alternative to a permanent magnet which produces a relatively low magnetic field. The superconducting magnet thruster was constructed by combining the magnet with the anode-cathode assembly of an MPD thruster developed by McDonnell Douglas. (7) Results obtained with this thruster are also reported on herein.

\section{Facilities and Measurement Techniques}

All experiments were performed in a 4.6 meter diameter, 19.8 meter long vacuum tank. The bockground pressure was from $10^{-5}$ to $10^{-4}$ torr. (8) The basic thruster configuration was the McDonnellDouglas X-7.(7) Gaseous propellant flow rates were measured by the use of small jeweled, sonic orificies calibrated for flow rate versus upstream pressure.

Thrust measurements were made using a parallelogram-pendulum thrust stand. The electrical power for the arc was brought onto the stand through coaxial electrodes in coaxial mercury pots. The power was supplied by commercially available welding power supplies. Deflection of the stand Was sensed by a linear differential transformer with output indicated on a strip chart recorder. The thrust stand was calibrated by a weight and pulley arrangement which was used to apply known forces to the stand. A 25-centimeter-diameter steel bucket or "thrust killer" was mounted on a shaft on the thrust stand and could be swung down in front of the thruster to remove the directed energy of the beam. The thrust could be measured by blocking the exhaust beam momentarily with the thrust kiliex and observing the change in thrust stand deflection.

When the superconducting magnet was on the stand, the thrust killer was not used. Thrust measurements were obtained by turning off the arc power and noting the change in thrust stand deflection. The thrust tare which resulted from changing current in the external circuit was mirimized by arrangement of the leads. This tare was frequently checked by shorting the anode to the cathode and varying the magnetic field strength and are supply current. This tare was always less than 10 percent of the corresponding thrust measurement and was repeatable within about 5 percent of the thrust. The polarity of the current tare was always such that ignoring it would result in underestimating thrust.

\section{Permanent Magnet Tests}

Magnet AssembIy

To determine the feasibility of a completely radiation cooled thruster, a McDonnel1-Douglas $X-7$ thruster $(7)$ was modified to eliminate the electromagnet. A compound permanent magnet was assembied from small pieces of Columax 9. The assembled magnet had a length of $15.2 \mathrm{~cm}$, inside diameter of $2.7 \mathrm{~cm}$, and an outside diameter of $11 \mathrm{~cm}$. The magnet was held together with hose clamps Fig. (1).

The maximum operating temperature for a permanent magnet is its Curie temperature. However, the maximum useful temperature is somewhat lower than the Curie temperature since the residual magnetic field is a gradual function of temperature. $(9)$ In addition, the crystal structure of the magnets may change if held at high temperature for long periods of time. In the Alnico and Columax series, the maximum temperature which does not cause a structural change is $823 \mathrm{~K}$. (9) At this temperature there is approximately a 12 percent reversible loss in the room temperature magnetic field. Therefore, the upper limit for the magnet was set at $823 \mathrm{~K}$. 
During the assembly of the thruster, two thermocouples were placed on the magnet. They axe marked $A$ and $B$ in Fig. 2. $A$ is on the front face of the magnet $1.9 \mathrm{~cm}$ from the centerline. $B$ is on the internal wall of the magnet midway between the magnet ends. Both thermocouples are between the magnet surface and the thermal insulation adjacent to the magnet (Fig. 2). The thermocouple locations were chosen in the region of maximum heat flux from the anode and cathode. The initial magnetic field was 0.080 tesla at the cathode tip. Although the magnet was not designed for optimum weight, the total thruster weight including magnet was only $18.1 \mathrm{~kg}$.

\section{Initial Tests of Permanent Magnet Thruster}

The permanent magnet thruster was operated on ammonia propellant. During initial tests, the arc power was varied from 12 to $20 \mathrm{~kW}$. Even at $12 \mathrm{~kW}$, however, the temperature distribution in the magnet was not acceptable. After some hours of operation, the temperature at point $B$ was $630 \mathrm{~K}$ and rising slowly. The temperature at point $A$, however, was $955 \mathrm{~K}$ and rising slowly. The thruster was shut off because of excessive temperature at point $A$.

The long thermal delay time in the initial runs indicated that the thermal insulation of the magnet was probably adequate, However, the comr pound magnet apparently could not properly conduct heat from the entry region to the outer surface from which it would be radiated. To overcome this difficulty, a copper "can" or heat distribution surface was added to the magnet assembly as shown in Figs. 1 and 2 . It consisted of a circular copper plate $0.635 \mathrm{~cm}$ thick and $11.4 \mathrm{~cm}$ in diameter welded, at the outer edge, to a cylinder $0.318 \mathrm{~cm}$ thick and $5.08 \mathrm{~cm}$ wide. This can was placed over the front end of the magnet as shown in Fig. 2. The thermocouple at point $A$ was now between the copper can and the magnet. After reassembling the magnet, copper can, and thruster, the magnetic field at the cathode tip was 0.053 tesla.

\section{Final Tests of Permanent Magnet Thruster}

The test runs performed after the addition of the copper shield clearly show a reduction in the operating temperature of the magnet. Table $I$ shows the steady state temperature of point A for various values of arc power. At $27 \mathrm{~kW}$, the highest power tested, the temperature was $835 \mathrm{~K}$, which was about the maximum allowed steady state temperature. It was noted that approximately 4 hours were required for the magnet and thruster to reach equilibrium temperature.

After the thermal tests, the magnetic field at the cathode tip was unchanged remaining at 0.053 tesla. The thruster was then disassembled, the magnet remagnitized, and the thruster reassembled. This raised the magnetic field at the cathode tip to 0.0635 tesla. A performance test of the thruster was made at this increased magnetic field and the results are shown in Fig. 3. The arc power was held constant at $24 \mathrm{~kW}$ and the ammonia mass flow rate varied from 0.02 to $0.08 \mathrm{gm} / \mathrm{sec}$. Also shown is a performance curve for the same thruster operated at $25 \mathrm{~kW}$ arc power and 0.14 tesla magnetic field strength provided by a water cooled electromagnet. The latter curve is taken from Fig. 10 of an earlier paper. (4). We have not yet determined whether the degraded performance obtained with the permanent magnet thruster was due to the relatively low magnetic field. Other possible reasons for the difference in performance are:

(1) The field produced by the permanent magnet did.not decrease as rapidly with axial distance as that produced by the water cooled magnet.

(2) The cathode and insulator ran hotter on the permanent magnet thruster.

(3) Thruster components were badly deteriorated by the time the performance measurements were taken.

\section{Superconducting Magnet Tests}

In previous MPD thruster experiments, thruster performance was studied over a limited range of magnetic field strength. (6) No dependence on magnetic field was found for overall arc efficiency at constant arc power and mass flow rate. It was found, however, that anode efficiency improved with increasing magnetic field. (6) The fraction of arc power which ended up as anode heat decreased somewhat with increasing applied field strength. Since anode heat flux limits the arc power of a radiation cooled thruster, it was felt that power capability might be extended by the use of much higher applied magnetic field. The motivation for extending power capability is partly illustrated by Fig. 4. Efficiency is plotted as a function of arc power for two different values of specific impulse and two different thrusters. The water cooled thruster data are obtained from previous measurements on the Aveo $\mathrm{X}-2 \mathrm{~A} .(6,10,11)$ The radiation cooled thruster data are obtained from previous measurements on the McDonnell Douglas X-7. $(7,4)$. Both thrusters show increased efficiency with increasing arc power. The potential efficiency of the radiation cooled thruster clearly suffers from its limited arc power capability.

Superconducting magnet tests were performed using the configuration of Fig. 5 and ammonia propellant. A superconducting magnet was installed on the anode-cathode assembly of a McDonnell-Douglas X-7 radiation cooled thruster. The magnet was protected from the high temperatures on the thruster by a water cooled copper plate. A platinum iridium thermocouple was installed in contact with the anode surface at the point indicated in Fig. 5. The effect of magnetic field on thruster power capability is shown in Fig. 6. The arc power was set near $25 \mathrm{~kW}$ at a normal operating magnetic field of 0.13 tesla at the cathode tip. After the thruster had come to thermal equilibrium, the thermocouple reading was noted. The magnetic field was then increased in steps to 1 tesla. At each magnetic field setting, the arc power was adjusted to the value which produced the previously noted equilibrium temperature reading. This, hopefully, was indicative of approximately constant heat flux to the anode. The indicated improvement in power capability with an order of magnitude increase in magnetic field was disappointingly small. Thrust measurements were not obtained for this configuration. 


\section{Hollow Cathode Tests}

In addition to the above test performed with a solid conical cathode (Fig. 7(a)), the superconducting magnet thruster was also investigated with a hollow cathode. The hollow cathode was designed and fabricated by McDonnell-Douglas and is shown in Fig. 7(b). Initial tests with this cathode were performed on argon propellant, since there were stability difficulties with $\mathrm{NH}_{3}$. Due to the high values of thrust observed, the performance of this combination was systematically studied over a range of magnetic field. The results are shown in Fig. 8.

Unlike previous thrusters tested, the performance of this thruster has a strong dependence on magnetic field strength. At $\theta$ given specific impulse, the efficiency increased with increasing field strength. At 1 tesla, the highest field tested, the arc efficiency exceeded 30 percent at 2000 seconds specific impulse. The data indicate that the improvement in performance with increased magnetic field up to 1 tesla was not leveling off. Increasing the magnetic field above 1 tesla would presumably result in even higher performance.

In this experiment, thrust measurements were obtained with great difficulty. The weight of the superconducting magnet thruster plus thrust killer exceeded the capacity of our stand. Consequently, thrust measurements were made without the aid of the thrust killer by the method previously described. In addition, the superconducting magnet requires that large vent and fill lines be brought onto the stand. This further compromised the quality of our thrust measurements. Because of all these difficulties, there was a fairly large spread in the data. Figure 9 shows all the thrust data obtained at 1 tesla, the highest magnetic field strength studied. The data was obtained by holding the arc power approximately constant near $25 \mathrm{~kW}$ and varying the mass flow rate. The thrust was not corrected for current tare since the indicated corrections were the same order as the scatter in the thrust measurements. Applying the current tare would slightly increase the quoted thrust.

\section{Concluding Remarks}

A completely radiation cooled MPD thruster was operated using a permanent magnet. The thermal problems were found to be quite manageable indicating the feasibility of a radiation cooled MPD thruster. However, the performance of the same thruster was somewhat higher when it uses the higher magnetic field produced by a water cooled magnet. The total thruster weight was under $1 \mathrm{~kg} / \mathrm{kW}$.

A radiation cooled MPD thruster was operated with a superconducting magnet to see whether increased magnetic field would improve arc power capability. The increase in power capability for an order of magnitude increase in field strength was found to be quite modest.

The same thruster-superconducting magnet system was operated with a hollow cathode and argon propellant. The performance of this combination improved dramatically with increasing magnetic field strength. At $25 \mathrm{~kW}$ arc power the efficiency exceeded 30 percent at 2000 sec specific impulse. There appears to be a possibility of even further increase in the efficiency of this thruster by using even higher magnetic field strength. We have not yet considered, however, whether the weight and complexity of a superconducting magnet system can be tolerated in this type of space propulsion device.

\section{$\underline{\text { References }}$}

1. Nerheim, N. M. and Kelley, A. J., "A Critical Review of the Magnetoplasmadynamic (MPD) Thruster for Space Applications," JPL-TR-321196, NASA CR-93139, Feb. 1968, Jet Propulsion Lab., California Inst. of Technology, Pasadena, Calif.

2. Seikel, G. R., Connolly, D. J., Michels, C. J., Richley, E. A., Smith, J. M. , and Sovie, R. J., "Plasma Physics of Electric Rockets," Plasmas and Magnetic Fields in Propulsion and Power Research, SP-226, 1970, NASA, Washington, D.C., pp. 1-64.

3. Johansen, A, E. and Palmer, R. W., "Lightweight Magnets for MPD Arcs," Paper 67-686, Sept. 1967, AIAA, New York, N.Y.

4. Connolly, D. J. and Sovie, R. J., "Performance of Radiation-Cooled Magnetoplasmadynamic Arc Thrusters," TM X-1908, 1969, NASA, Cleveland, Ohio.

5. Connolly, D. J., Sovie, R. J., and Seikel, G. R., "Performance and Diagnostics of a Water-Cooled Magnetoplasmadynamic Arc Thruster," TN D-5836, 1970, NASA, Cleveland, Ohio.

6. Connolly, D. J., Sovie, R. J., Michels, C. J., and Burkhart, J. A., "Low Environmental. Pressure MPD Arc Tests," AIAA Journal, Vol. 6, No. 7, July 1968, pp. $1271-1276$.

7. Esker, D. W., Kroutil, J. C., and Checkley, R. J., "Radiation Cooled MPD Arc Thruster," Rep. H296, NASA CR-72557, July 1969, McDonnell Res. Labs., St. Louis, Mo.

8. Finke, R. C., Holmes, A. D., and Keller, T. A., "Space Environment Facility for Electric Propulsion Systems Research," TN D-2772, 1965, NASA, Cleveland, Ohio.

9. Parker, R. J. and Studders, R. J., Permanent Magnets and Their Applications, Wiley, New York, 7962, p. 323.

10. John, R. R. and Bennett, S., "Arcjet Technology Research and Development," Rep. RAD-JR65-5, NASA CR-57452, Dec. 1964. Avco Corp., Washington, Mass.

11. Jones, R. E. and Walker, E. L., "Status of Iarge Vacuum Facility Tests of MPD Arc Thruster," Paper 66-117, Jan. 1966, AIAA, New York, N.Y. 
Arc power, Maximum magnet

$\mathrm{kW}$

temperature,

$(\mathrm{OK}) \cdot($ point $\mathrm{A}$ )

16.0

750

20.0

23.5

775

27.0

800

Table I 


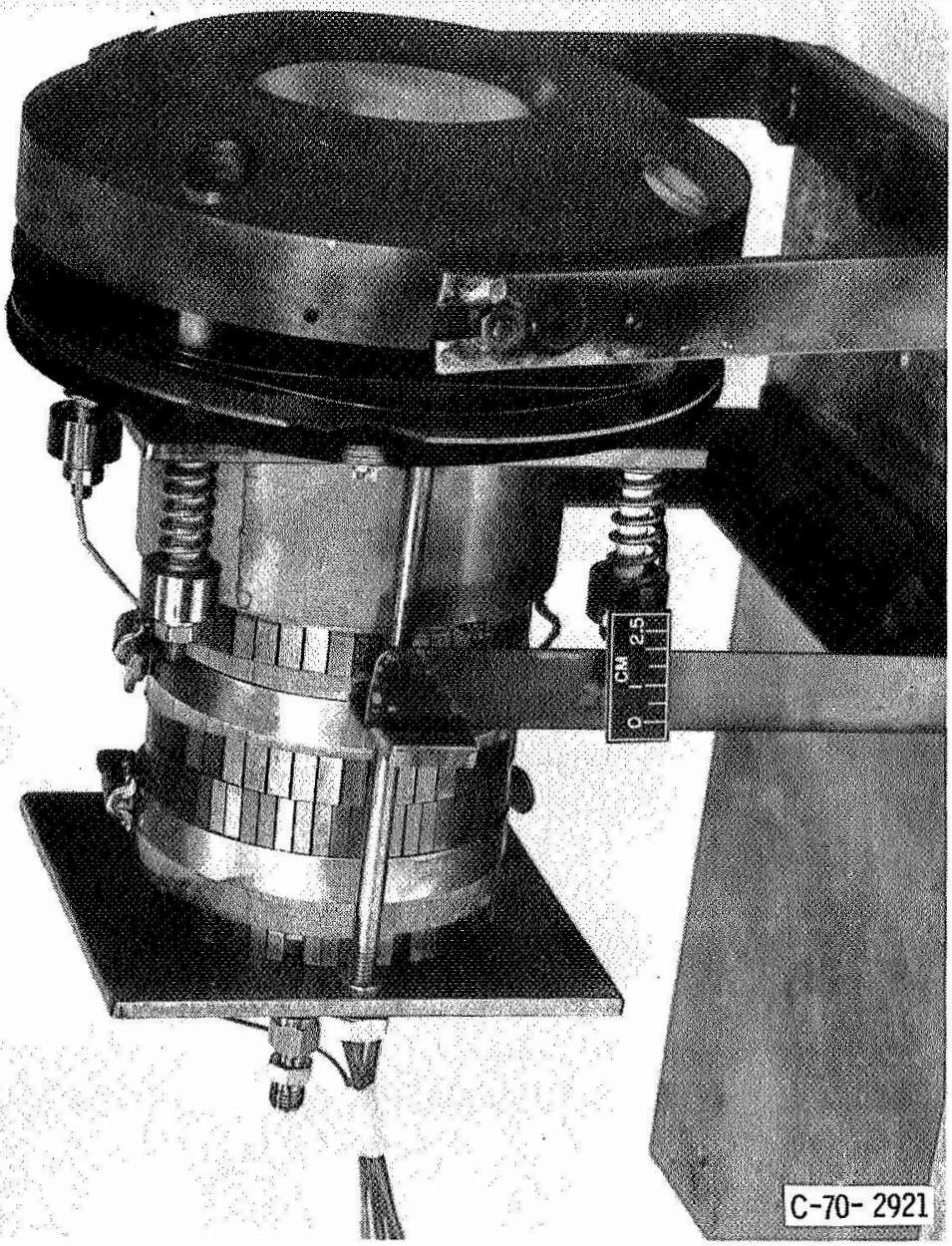

Figure 1. - Permanent magnet thruster with copper can installed. 


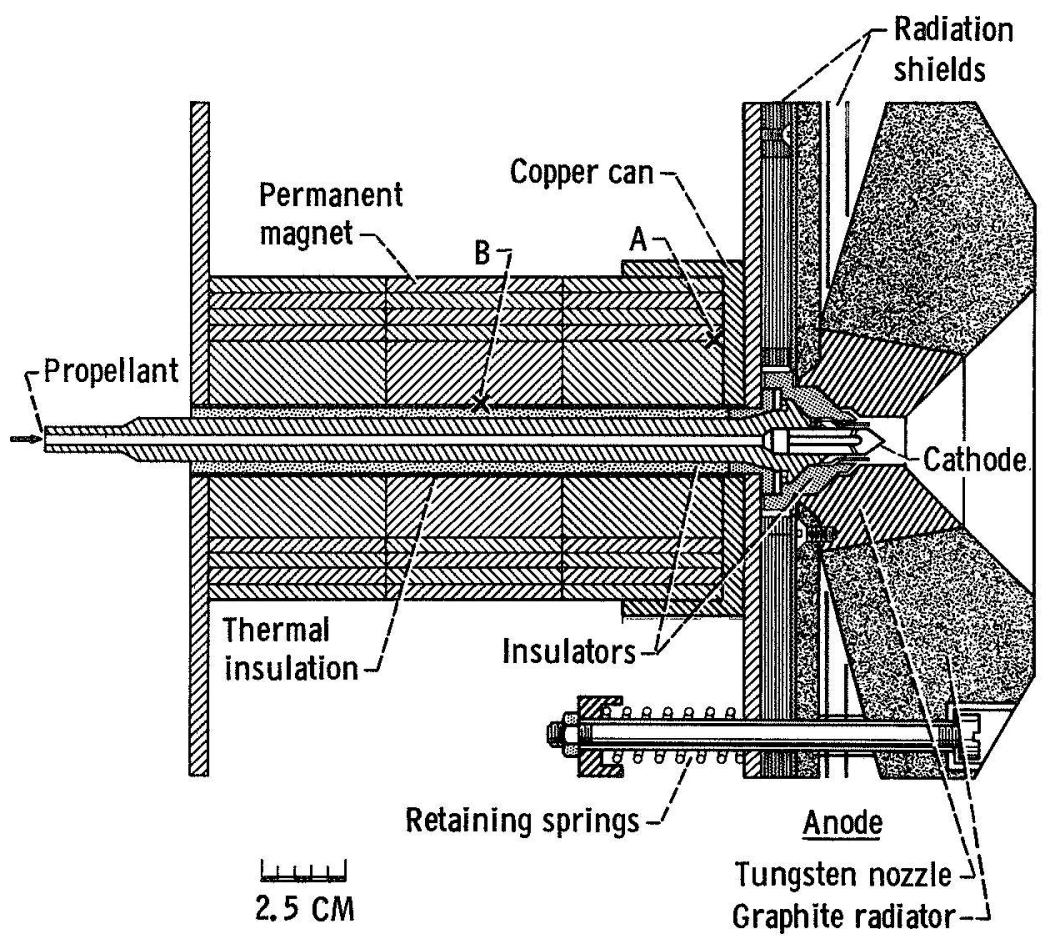

Figure 2. - Permanent magnet thruster with copper can installed.

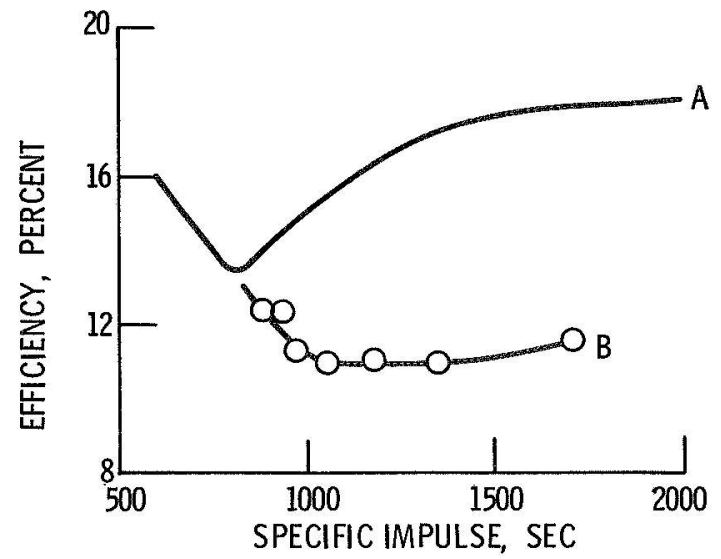

Figure 3. - Comparison of thrust efficiency as a function of specific impulse for a permanent magnet thruster and electromagnet thruster.

A. Water cooled electromagnet, arc power = $25 \mathrm{~kW}, \mathrm{~B}=0.14$ tesla.

B. Permanent magnet, arc power $=24 \mathrm{~kW}$, $B=0.0635$ tesla. 


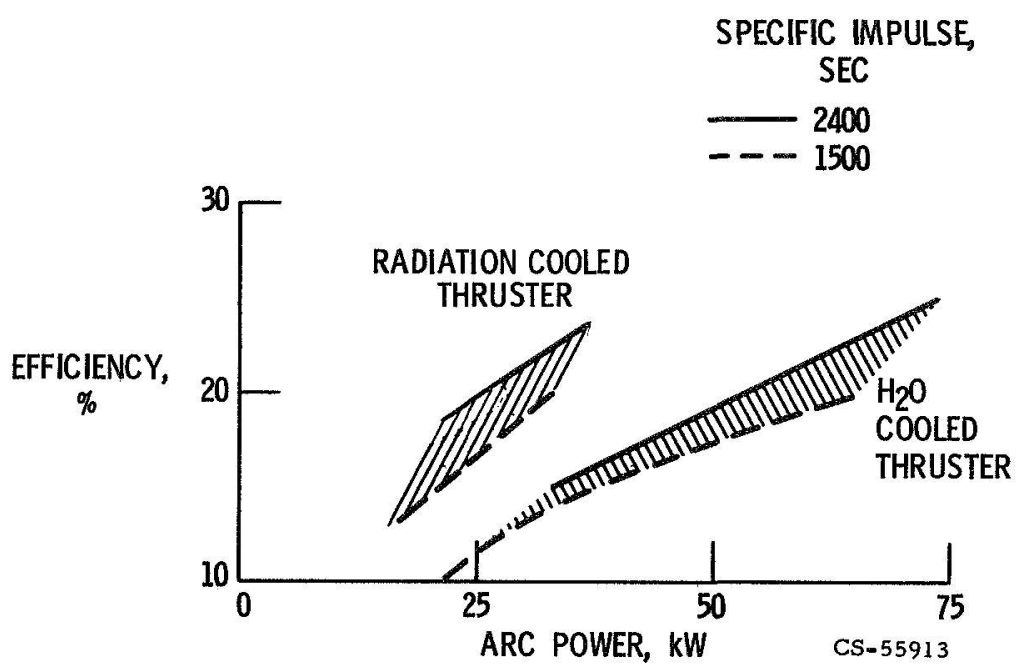

Figure 4. - Trend of MPD thruster efficiency as a function of arc power.

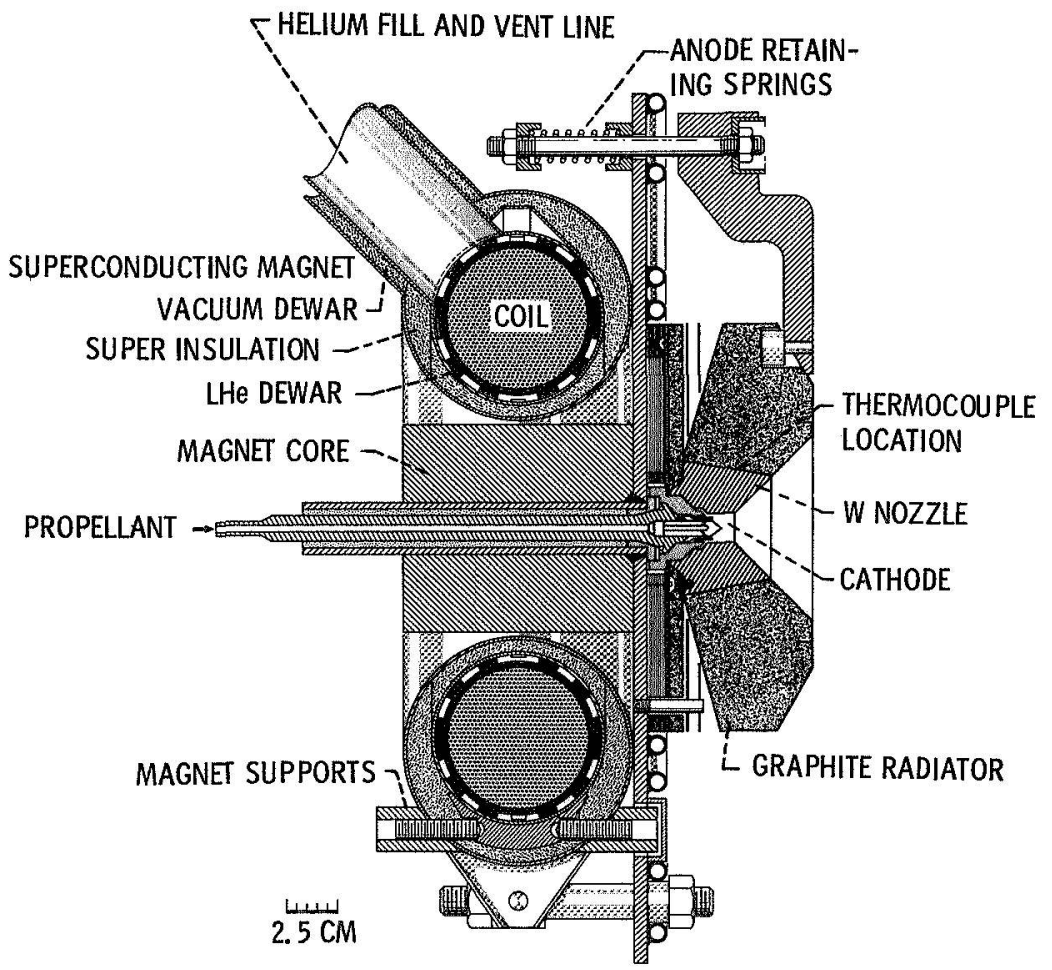

Figure 5. - Superconducting magnet thruster. 


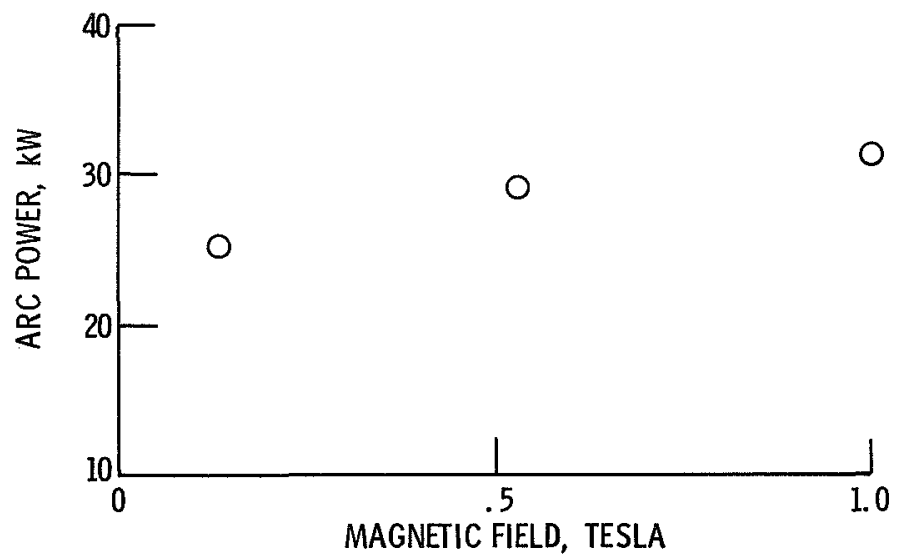

Figure 6. - Arc power as a function of cathode tip magnetic field strength at constant anode temperature. 

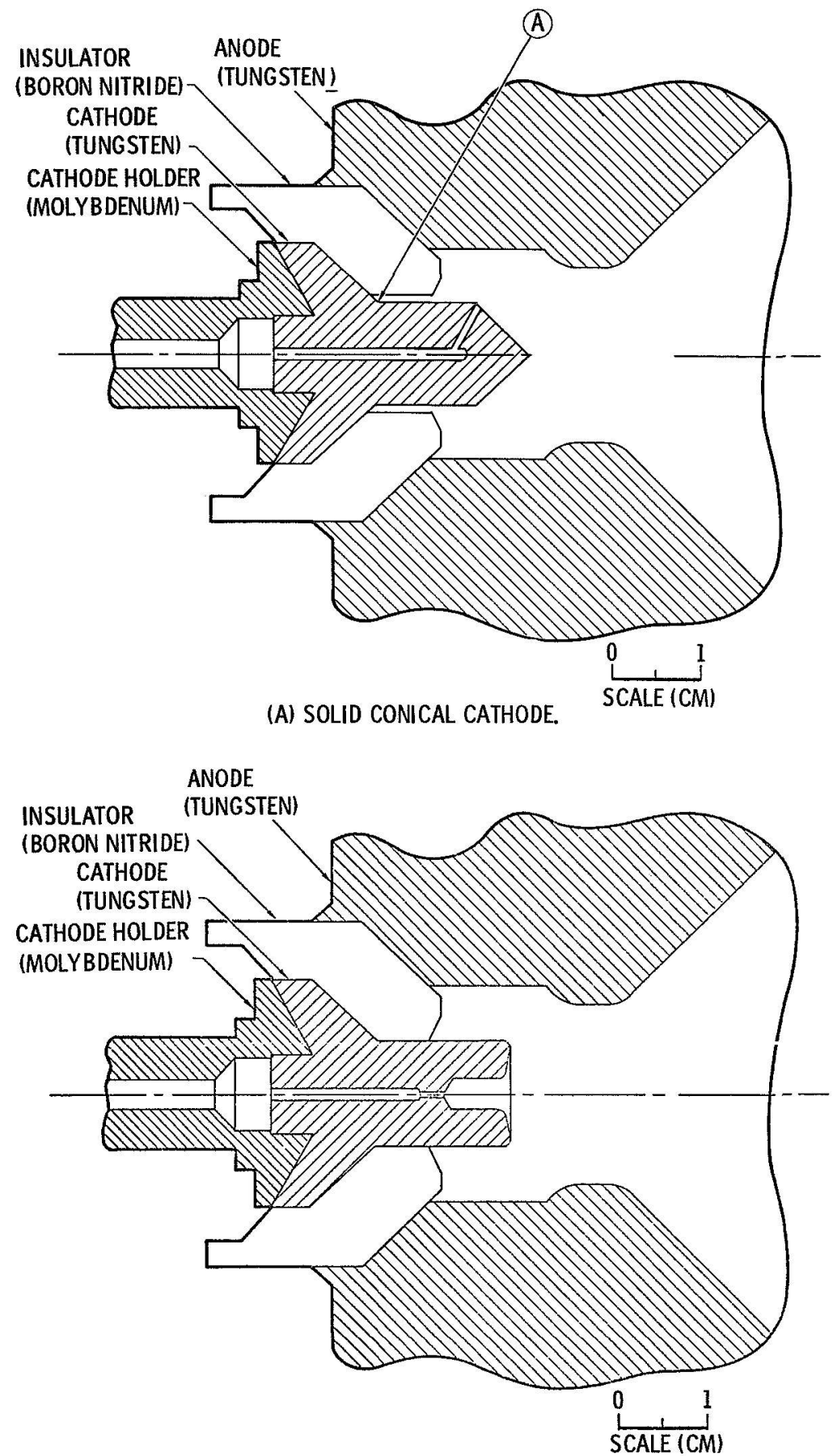

(B) HOLLOW CATHODE.

Figure 7. - Radiation cooled cathode-insulator assemblies. 


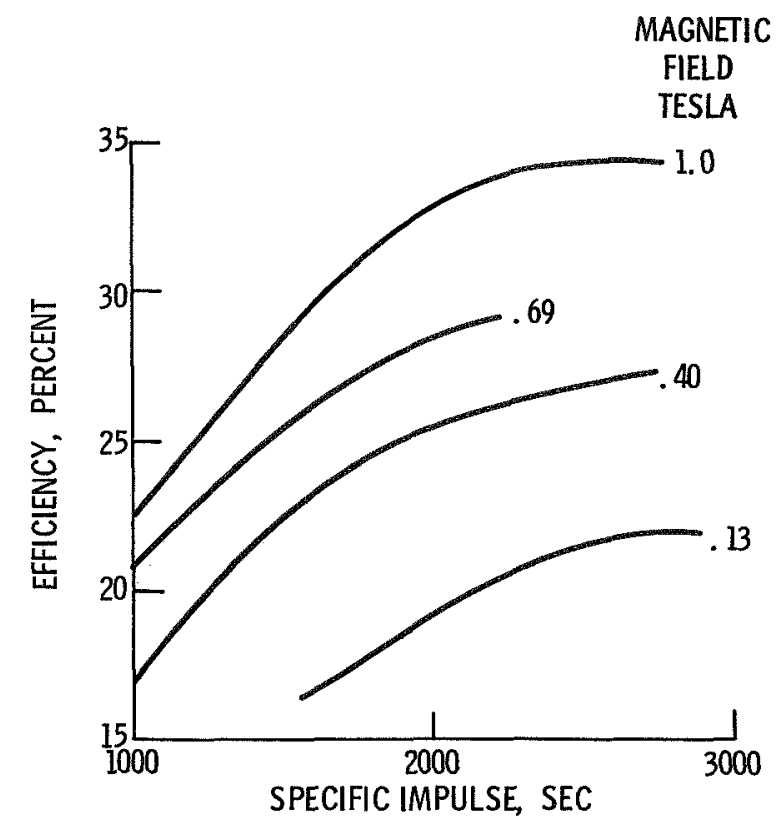

Figure 8. - Performance of superconducting magnet thruster with hollow cathode and argon propellant.

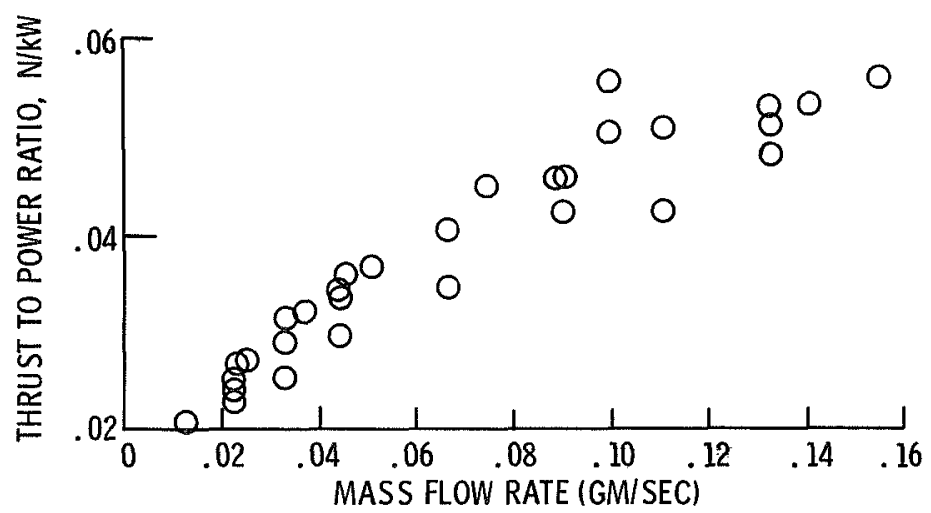

Figure 9. - Thrust to power ratio as a function of propellant mass flow for a hollow cathode thruster with argon propellant. Magnetic field $=1$ tesla, arc power $\approx 25 \mathrm{~kW}$. 